\title{
SOCIO-PSYCHOLOGICAL FACTORS THAT INFLUENCE CAR PREFERENCE IN UNDERGRADUATE STUDENTS: THE CASE OF THE CZECH REPUBLIC
}

\author{
Denis ŠEFARA, Marek FRANĚK, Václav ZUBR \\ Department of Management, Faculty of Informatics and Management, \\ University of Hradec Králové, Rokitanského 62, 50003 Hradec Králové, Czech Republic
}

Received 15 April 2015; accepted 10 May 2015

\begin{abstract}
The present study examined the socio-psychological factors (personality dimensions, motives for car use, and materialistic values) that influence car preference in undergraduate students $(\mathrm{N}=383)$. Preferences for particular car types, properties, and brands were studied. The data indicated only a slight correspondence between the personality dimensions of the Big-Five model and car preference. However, individual motives for car use and materialistic values predict preferences for certain car types and even more for car brands. The results demonstrated a clearly defined group of individuals who prefer cars with high performance. These individuals prefer German cars of "prestigious" brands, such as Audi, BMW, and Mercedes-Benz. For these individuals, affective motives, as well as materialistic values are important cues for car use and preference. These findings are discussed in terms of more sustainable modes of travel and campaigns to promote sustainable travel modes. The potential value shift from cars as objects that represent personal freedom and identity to more recent mobile technologies, which might play the same role in the younger generation, is discussed.
\end{abstract}

Keywords: car preference, Big-five personality model, socio-psychological factors, motives for car use, sustainable modes of travel.

JEL Classification: M31, R40, Z13.

\section{Introduction}

The reduction of $\mathrm{CO}_{2}$ emissions and use of non-renewable resources require the promotion of more sustainable modes of travel. Successful campaigns that promote sustainable modes of travel require a deeper understanding of the socio-psychological processes that lead individuals to use cars over other forms of transportation. Individuals buy and use cars

Corresponding author Marek Franěk

E-mail: marek.franek@uhk.cz 
for different reasons. Clearly, a car purchase, similar to the purchase of other products, is primarily determined by economic factors, such as the price, operating costs and other car properties, as well as the financial situation of the customer. Cars can also represent objects for non-verbal communication of individual achievements and success, as well as identities and social positions (Gatersleben 2014). Thus, car ownership has not only an instrumental value but also a symbolic meaning. For many drivers, driving a car has an affective value because driving can elicit pleasant feelings of thrill and excitement (Steg et al. 2001). Moreover, there is a popular belief that car preference could also reflect the behaviour, personality traits, and individual characteristics of the driver.

Although there are numerous socio-psychological factors that influence car choice, most published investigations have examined economic or socio-demographic factors that influence customer intentions and preferences. For example, Lave and Train (1979) examined the influences of the purchase price, age, and a number of household members on car choice. Manski and Sherman (1980) studied the effects of a purchase price, a number of seats, an acceleration time, a luggage space and operating costs. Mannering and Winston (1985) investigated the purchase price and operating costs. Variables such as age, gender, college degree, number of household members, and income were examined in Kitamura et al. (2001). Bhat, Sen and Eluru (2009) studied the effects of household demographics, household location characteristics, built environment attributes, household head characteristics, and vehicle attributes on household vehicle holdings and use. Several studies have also investigated spatial interdependence effects in vehicle ownership (Adjemian et al. 2010) and the influence of neighbourhood characteristics on vehicle-type choice (Potoglou 2008).

Steg et al. (2001) distinguish between instrumental-reason and symbolic-affective motives for car use. While the former refers to the general instrumental function of car use, the later describes the symbolic functions of cars. Recently, several investigations have focused on an effect of symbolic motives on car selection. It was demonstrated, for example, that women consider men more attractive in premium, representative cars compared with common cars (Dunn, Searle 2010). Owners of sports cars can look younger (Effendi, Whitfield 2012). Adolescents particularly attempt to gain prestige through clothes and car ownership (e.g., Suitor et al. 2003). While driving a car can be a stressful activity, positive emotional reactions are associated with the use of a car during leisure rides (Anable, Gatersleben 2005). In the leisure rides aspects of driving, such as excitement, freedom, and relaxation, fully appear. Large and powerful cars can be perceived as a symbol of success and provide their owners a sense of pride and enthusiasm when driving (Gärling et al. 2013). A car can also be perceived as the primary territory, similar to a home (Fraine et al. 2007). Self-esteem is associated with car type in men (Ellaway et al. 2003).

The ownership of material goods is closely related to materialist values. There is a connection between materialism and attitudes towards cars. Materialistically oriented individuals like to exhibit their social status through material goods. Individuals with a materialistic orientation do not want to purchase energy-saving cars (Gatersleben 2011).

Interestingly, there are also stereotypical images regarding personal qualities of owners of particular car types or even regarding owners of individual car brands. For example, research conducted in Germany (Fischer 2009) identified various personality stereotypes 
associated with owning particular car brands. It was demonstrated that Audi drivers are viewed as attractive and audacious. BMW owners are perceived as wild and masculine. Fiat drivers are thought to be slim and restrained, whereas Ford drivers are viewed as corpulent and shy. Mercedes drivers are serious and bourgeois. A typical Opel driver is honest and good-humoured. Peugeot drivers are viewed as pretty and cosmopolitan, and Volkswagen owners are happy and modest. Recent research suggests that individuals tend to see human faces in car fronts (Kühn et al. 2014; Windhager et al. 2012). Curiously, in the most recent study, Stieger and Voracek (2014) demonstrated that cars resemble their owners in the same way as their dogs. Their study indicates that raters were successful at matching car owners to the front views of their cars. These findings suggest that some individuals might be attracted to certain car brands, which may express their personalities and identities.

In the previous decade, several studies have appeared that have documented manifestations of personality in various everyday behaviours. The Big-Five personality model has been frequently used, which describes personality in the five dimensions: neuroticism, extraversion, openness, consciousness, and agreeableness (e.g., John, Srivastava 1999). These studies have consistently demonstrated that personality traits are, to some extent, predictors of preferences for musical genres that an individual likes (Rentfrow, Gosling 2003), his/her physical appearance (Naumann et al. 2009), arrangement of personal space (Gosling et al. 2002), the design of personal websites (Vazire, Gosling 2004), and political preferences (Carney et al. 2008). However, there is a lack of knowledge about the relationship between Big-Five personality traits and consumer behaviour. Similarly, the studies concerning associations between personality and car choice were not conducted. Only authors Choo and Mokhtarian (2004) examined the relationship between personality and car type choice. Their data demonstrated that "adventure seekers" typically tend to prefer sports cars. Moreover, adventure seekers dislike compact, mid-sized, large vehicles and minivans. "Loners" liked small vehicles and SUVs and disliked mid-sized vehicles and minivans. Calm individuals liked minivans, small and compact vehicles and disliked sports cars and SUVs. The drawback of the study is that the authors did not use any standardized test of personality.

In accordance with gender stereotypes, there is a popular believe that women have different patterns of car preferences. Several studies confirmed that women's patterns of car buying differ from those of men (e.g. Moutinho et al. 1996). Typically, women tend to buy lowerpriced cars, and prefer the compact and subcompact segments (Candler 1991).

The aim of the present study was to extend our knowledge regarding various socio-psychological factors that influence car preference in undergraduate students. To promote more sustainable modes of travel, it appears important to attempt to further understand motives for car use, values and personality characteristics and their associations with car choice. There is existing literature regarding the socio-psychological factors that influence car use (e.g., Dittmar 1992, 2004; Gatersleben 2007; Steg et al. 2001; Steg 2005). However, there is still a lack of empirical data regarding the factors that determine preference of particular car types and brands and their relationship to motives and other socio-psychological factors for car use. Moreover, the previous studies have only originated from Western European countries. Recent investigations suggest that even preference of particular brands could reflect the personal and social identities of their owners. A question arises as to whether robust and 
consistent differences between individuals who prefer various types or brands of cars exist. If so, which socio-psychological factors caused these differences? How are these differences influenced by personal factors, motives for car use or an individual value system?

To identify car preference, one approach is to ask car owners which vehicle they have and investigate the described socio-psychological variables. However, there may be differences between the preferred cars and vehicles that the individual actually owns. These differences may be especially true for the post-communist countries, where the living standard remains lower than in Western Europe and the U.S.A.. It makes cars to be relatively expensive. Many customers cannot purchase a car that they would like to own. It is true not only for cars of "premium" brands, but also for more common cars. Moreover, various instrumental-reasoned motives also play roles in an actual car purchase (e.g., a need to transport children and family or allocate money for other household demands). Thus, for this type of research, undergraduate students represent a good research sample. Although there has been extensive discussion concerning the use of university students as test subjects, we believe that they fit well for this study. The university students are still not employed and do not have their own families; thus, they may not be influenced by the previously described instrumental-reasoned factors. It appears that undergraduates can spontaneously express their preferences and wishes. Moreover, the university students are future buyers of cars and therefore their preferences are important if we want to understand what car choices will be made in the future. Clearly, the budgets of undergraduates are rather limited. Thus, to encourage participants to freely express their wishes and preferences, we decided to introduce a scenario in which a participant had sufficient financial resources and could choose a car according to his/her preferences.

In summary, the objectives of the present study were to examine the broader range of socio-psychological factors that influence car use in undergraduate students and consider these factors in the context of preferences for particular car types, properties, and brands.

\section{Methods}

\subsection{Participants}

Three hundred eighty-three respondents participated in the study. The participants were all undergraduate students from the Faculty of Informatics and Management at the University of Hradec Králové. The respondents ranged in age from 18 to 27 years, and their mean age was 21.1 years $(S D=1.17,210$ females). The sample was relatively homogenous because all participants studied management, economics and partly informatics.

\subsection{Measures}

Car preference questionnaire. First, in a pilot investigation, thirty participants were asked to describe their levels of familiarity with various characteristics and properties of cars and particular car brands. The group of participants consisted of undergraduates from the Faculty of Informatics and Management at the University of Hradec Králové. Next, the car preference questionnaire was constructed. The pilot investigation assured that the study participants were highly familiar with the subjects of the study. The questionnaire was introduced with 
the scenario "Imagine that you have enough money and can buy a car that you like". The questionnaire consisted of items that describe the main characteristics of cars. The questionnaire comprised items that describe the type of a vehicle (car, off-road, sport), vehicle body (e.g., hatchback, sedan, estate, limousine, and sport utility vehicles), fuel type, fuel consumption, size, distinctiveness, performance, and car brand. The participants were asked to rate their level of preference using a 1-5 scale (strongly dislike - strongly like).

Demographics. The participants' gender, age, frequency of driving, and vehicle ownership were determined.

Personality. Personality was assessed using the Czech translation of the Ten-Item Personality Inventory (Gosling et al. 2003). The inventory consists of ten items, and each pair of items corresponds to each of the Big-Five personality dimensions - Extraversion (Cronbach's alpha $=0.68)$, Stability (Cronbach's alpha $=0.51)$, Consciousness (Cronbach's alpha $=0.45$ ), Agreeableness (Cronbach's alpha $=0.22$ ), and Openness (Cronbach's alpha $=0.56$ ). The level of agreement/disagreement with the items was expressed on a 7-point Likert-type scale. The reliability of the traits Extraversion, Stability, Consciousness, and Openness was similar to the original English version (Gosling et al. 2003). Only the dimension Agreeableness (Cronbach's alpha $=0.22$ ) is not considered sufficiently reliable.

Motives for car ownership. Based on a study by Steg (2005), a sixteen-item questionnaire was created, which measured symbolic motives (e.g., "I can express myself through my car, my car shows what I am."; Cronbach's alpha = 0.81), affective motives (e.g., "I consider driving as enjoyable."; Cronbach's alpha $=0.84$ ), instrumental-reasoned motives (e.g., "The car serves as a loading space for luggage, shopping, etc."; Cronbach's alpha $=0.58$ ), and independence motives (e.g., "Thanks to the car, I am independent of the other."; Cronbach's alpha $=0.75$ ) for car purchase. The level of agreement/disagreement with these items was expressed on a 5-point Likert-type scale.

Materialism. To measure materialism in consumers, the Czech translation of the nine item version of the Material Values Scale (Richins 2004) was used. The scale consists of items that describe the importance of material values manifested in consumer behaviours, such as "I admire people who own expensive homes, cars, and clothes", "I like to own things that impress people", and "I'd be happier if I could afford to buy more things". The level of agreement/disagreement with these items was expressed on a 5-point Likert-type scale. The scale has acceptable psychometric properties (Cronbach's alpha $=0.80$ ).

\section{Results}

The descriptive statistics of all variables were calculated. All statistical analyses were conducted using Statistica 12 software. The descriptive statistics for preferences regarding car body, fuel type, transmission type, car size, car appearance, performance, and equipment are reported separately for males and females in the Supplemental online material. The significance of gender differences was tested via a $t$-test for independent samples.

The data demonstrated that sports vehicles are primarily preferred in males, whereas SUVs are primarily preferred among females. Limousines and off-roads were less preferred cars in both genres. The participants preferred more gasoline or diesel fuels over LPG or hybrid and 
electric cars. The interest in fuel consumption is higher in females than in males. Compared with the female participants, the male participants preferred cars with a high performance and a higher level of equipment. Furthermore, the preferences of particular car brands were analysed (see the Supplemental online material). The data demonstrated that brands such as Audi, BMW, Mercedes-Benz, Volkswagen, and Škoda were highly preferred over the other brands. The level of preference was mostly higher in males compared with females. In contrast, Dacia and Fiat were less preferred brands. Males disliked these cars more than females.

In further analyses, we examined the relationships between the preferences of individual car types and car properties and personality traits, dimensions of car ownership motivations, materialist values, and attitudes towards motoring.

The set of statistical models that predicted preferences of individual car types and car properties based on the multiple regression analysis was calculated. Personality traits (extraversion, agreeableness, consciousness, emotional stability, and openness), motives (symbolic, affective, instrumental-reasoned, and independence), materialistic values, and attitudes towards motoring were chosen as the predictor variables. The data were calculated separately for males (Table 1) and females (Table 2).

In males, the results indicated that the greatest predictive value had the models for preferences for high car performance, preferences for distinctive cars, preferences for high level of equipment, interests in car consumption, and preferences for alternative fuelling types. Particular personality traits (extraversion, agreeableness, consciousness, emotional stability, and openness) were poor predictors for preferences for individual car properties. Extraversion was the significant predictor for preferences for sports cars and distinctive car appearance. Agreeableness significantly negatively predicted preferences for hatchbacks. Emotional stability significantly positively predicted preferences for sedans and negative for preferences for estates. Openness significantly positively predicted preferences for hybrid or electrical fuelling, as well as with preferences for sports cars. We did not found any significant associations between consciousness score and car type preferences. In general, the regression models showed that personality can explain only a small portion of preference for particular types of cars and car properties.

However, individual motives for car use can explain more differences in the preference for car type and properties. The symbolic motives were the significant predictors for preferences for sports cars, off-roads, and hybrid or electrical fuelling. The affective motives were the significant positive predictors for preferences for large cars, distinctive car appearance with a high performance, and fuel type gasoline, and negative predictors for interest in car consumption. The instrumental-reasoned motives were the significant positive predictors for interest in car consumption, preferences for large cars, and preferences for SUVs and negative predictors for preferences for sedans and a high performance. The materialistic values were positively associated with preferences for limousines and a higher level of equipment. The attitudes towards motoring did not significantly influence car preferences.

Table 2 shows the results for females. Among females, only the models for preferences for high car performance had the higher predictive value. The data indicated that openness was the significant positive predictor for preference for hybrid/electric cars, as well as large cars and the negative predictor for preference for hatchbacks. Consciousness was the significant 


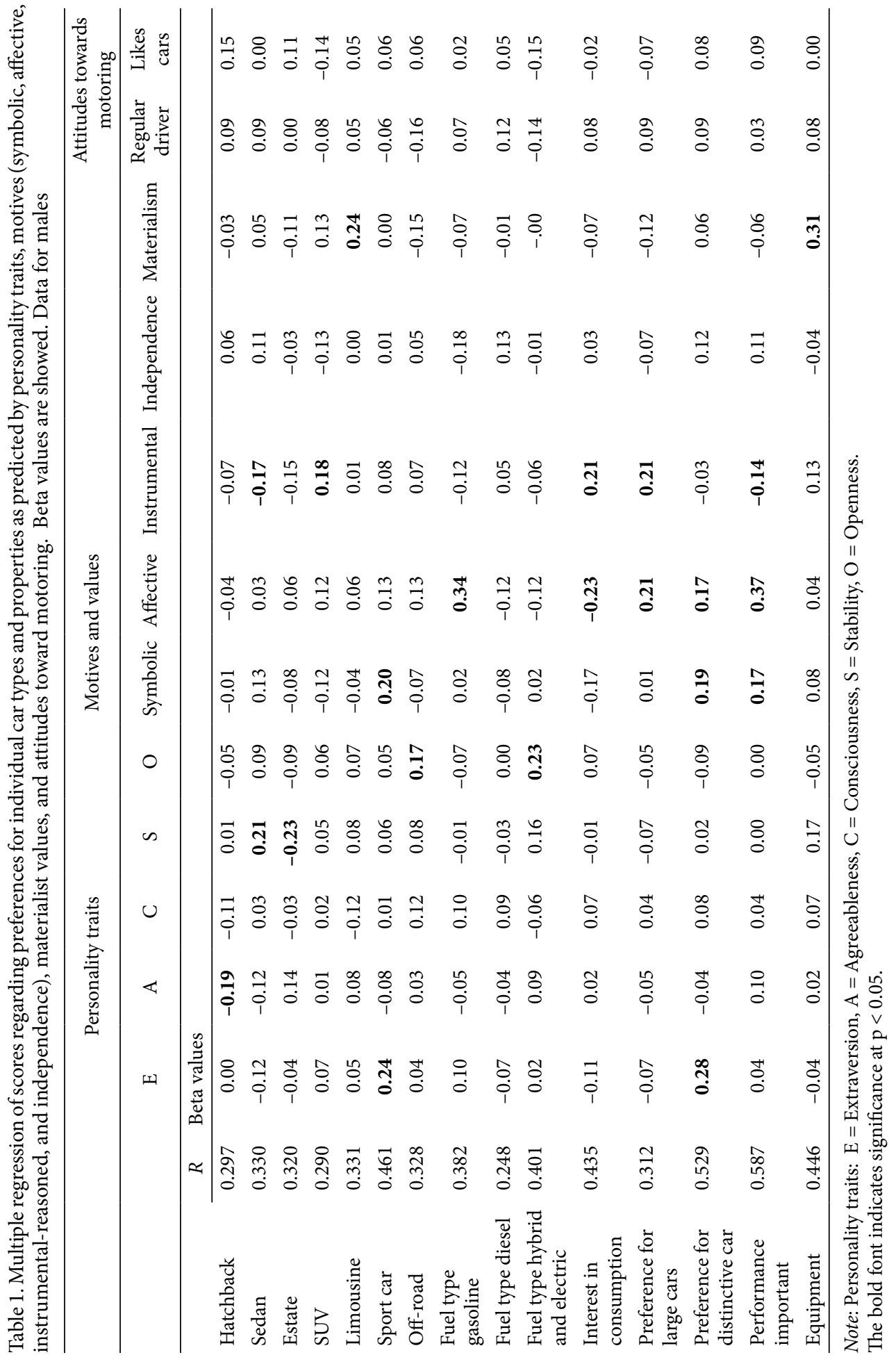


$\hat{0}$
है
है

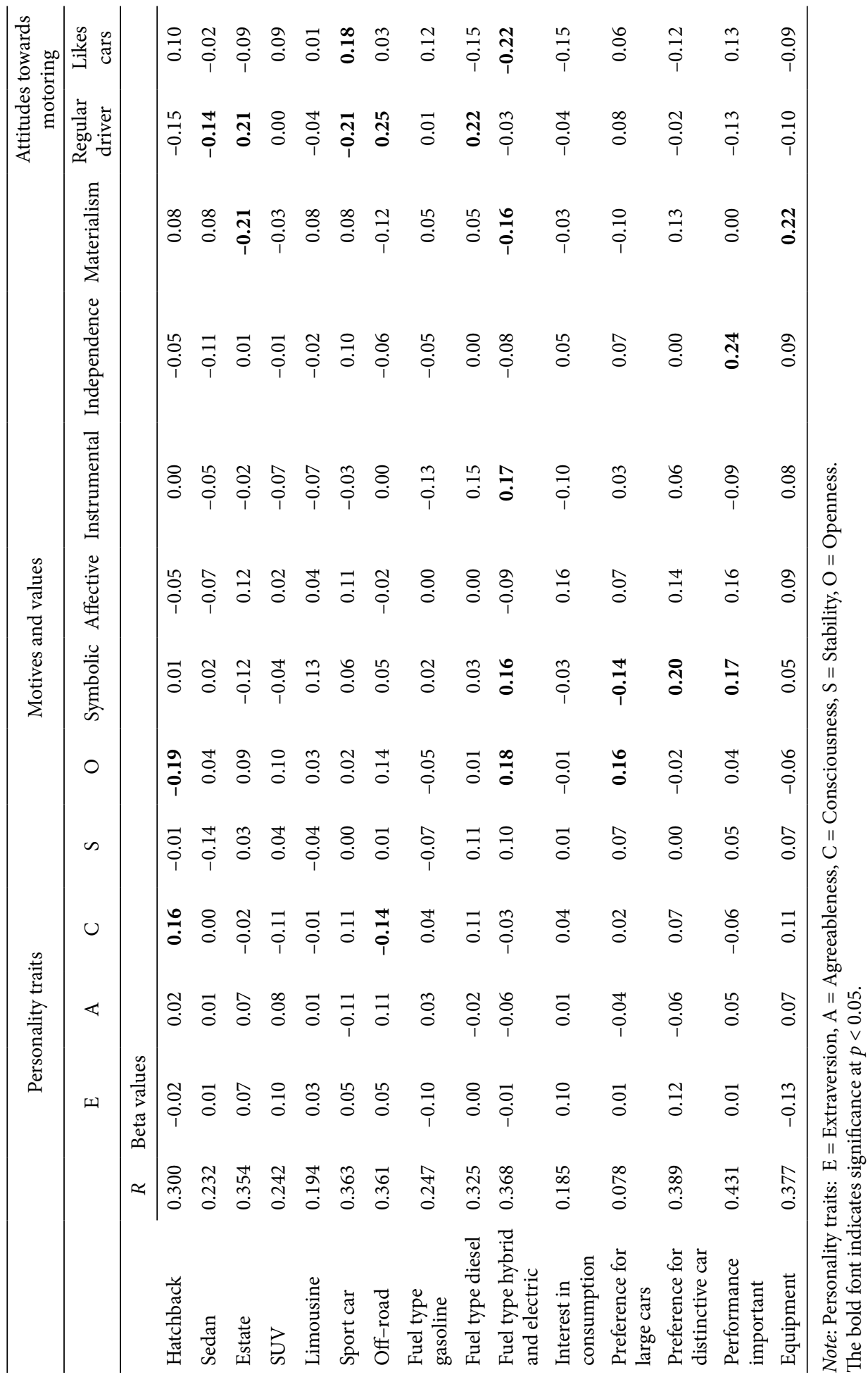


positive predictor for preference for hatchbacks and the negative predictor for preference for off-roads. Regarding gender differences, that data indicated that extraversion was only significant predictor for car preferences in males.

The symbolic motives were significant positive predictors for preferences for distinctive car appearance with high performance, and for hybrid or electrical fuelling, and negative predictors for preference for large cars. The affective motives did not significantly predicted car preferences. The instrumental-reasoned motives were the significant predictors for preferences for hybrid or electrical fuelling. The motives for independence were positive predictors for cars with high performance. The materialistic values were positively associated with preferences for higher level of equipment and negatively associated with preferences for estates and cars with hybrid or electrical fuelling.

The regular driving was the significant positive predictor for preferences for estates, offroads, and diesel fuel type and the negative predictor for preferences of sedans and sports cars. The car liking was the significant positive predictor for preferences for sports cars and the negative predictor for hybrid or electrical fuelling.

The subsequent analysis was devoted to factors that influence preferences for particular car brands (Table 3 for males and Table 4 for females). The set of statistical models that predicted preferences of individual car brands based on the multiple regression analysis was calculated. Personality traits (extraversion, agreeableness, consciousness, emotional stability, and openness), motives (symbolic, affective, instrumental-reasoned, and independence), materialistic values, and attitudes towards motoring were chosen as the predictor variables. Openness was the significant positive predictor for preferences for Ford and Opel. Consciousness was the significant positive predictor for preference for Citröen and the negative predictor for preference for Ford. Neuroticism was the significant predictor for preferences for Renault and Opel. Agreeableness was the significant negative predictor for preferences for Ford. Extraversion was the significant negative predictor for preferences for Ford. As we can see, the results indicated that personality traits are poor predictors for preferences for particular car brands and some significant associations are difficult to explain.

The data indicated that the symbolic motives were also poor predictors for preferences for particular car brands. It was shown that these motives significantly positively predicted preferences for Mitsubishi. Moreover, they significantly negatively predicted preferences for Dacia. Dacia is perceived as "cheap" brands of a low technical quality in the Czech Republic. Conversely, the affective motives played more important role. The affective motives were significant predictors for preferences for German "premium” brands, such as Audi, BMW, and Mercedes-Benz, as well as the Japanese cars Mitsubishi and Nissan and off-road Jeep, which do not very frequently occur in the car market of the Czech Republic. The materialistic values were significant positive predictor for Audi and negative predictors for preferences for Ford, Mazda, and Renault.

The regular driving was the significant negative predictor for preference for Fiat, which is perceived as a vehicle a low technical quality in the Czech Republic, as well as for cross-roads Jeep and Land Rover. The car liking was the significant negative predictor for preference for Kia, which is also perceived as "cheap" brands of a low technical quality in the Czech Republic. 


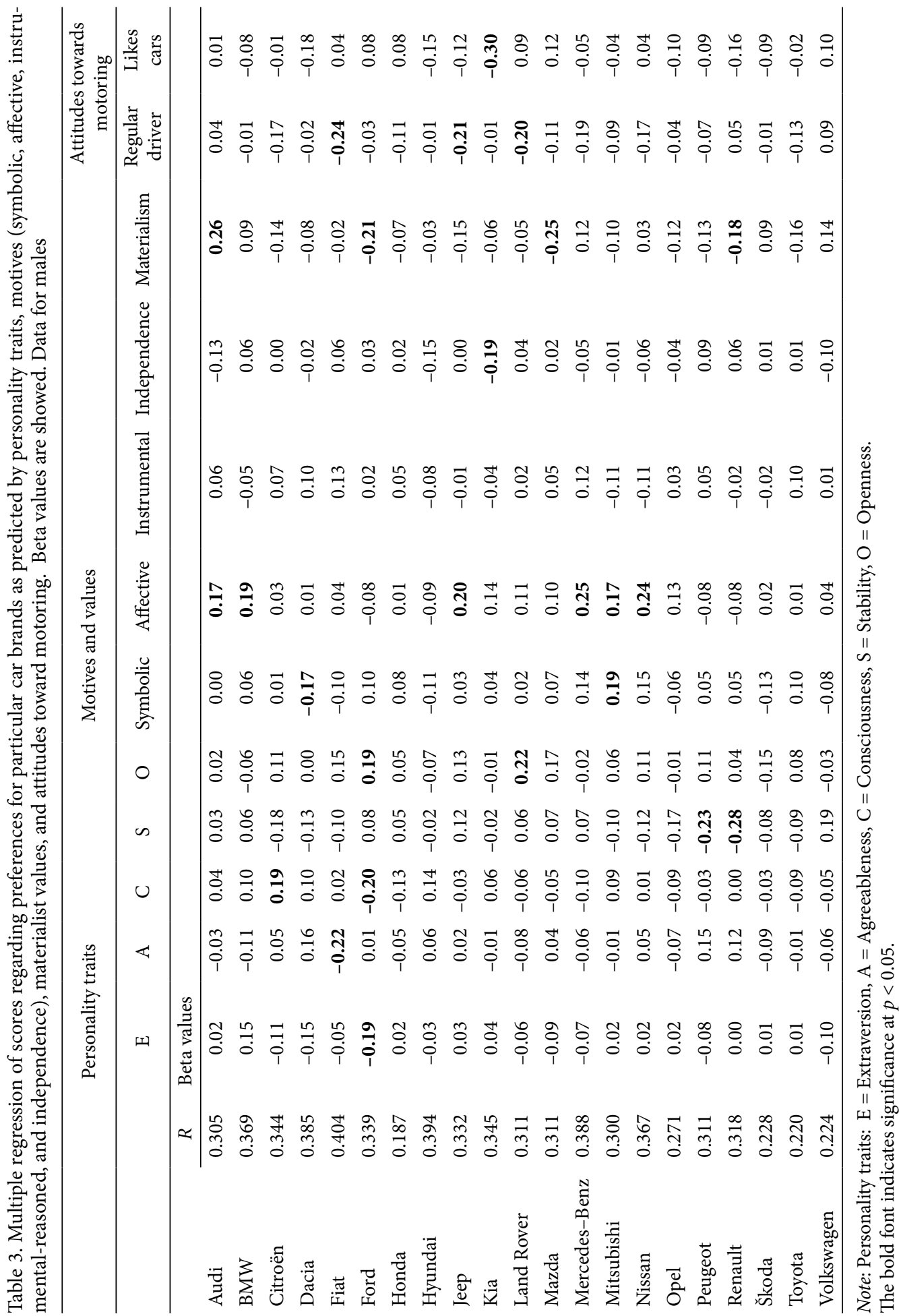




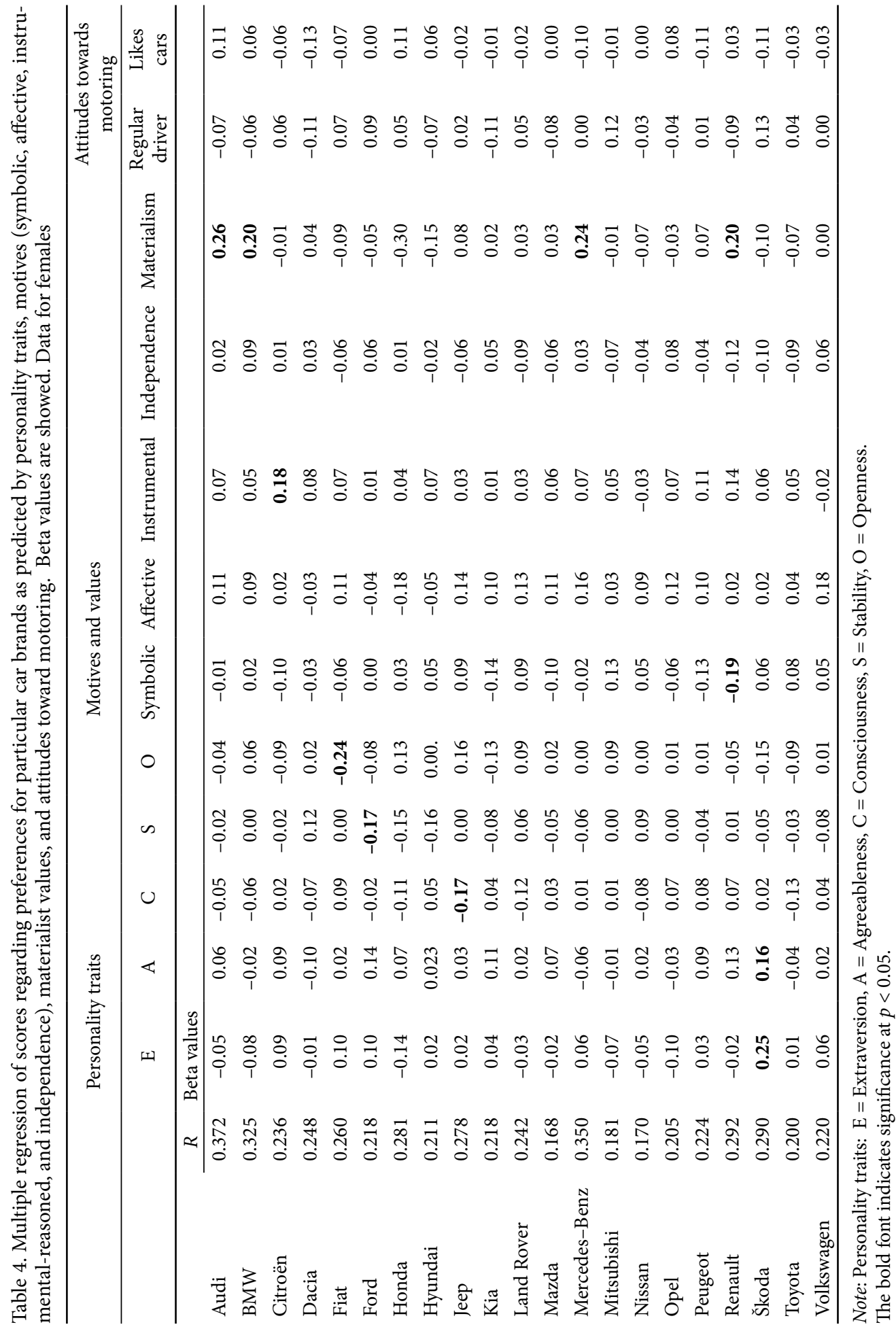


In females (Table 4), personality traits, motives, materialistic values, and attitudes towards motoring predicted car preferences in much lesser extent than in males. Extraversion and agreeableness were the significant predictors for preferences for Škoda. Openness was the significant negative predictor for preferences for Fiat, consciousness was the significant negative predictor for preferences for Jeep, and finally emotional stability was the significant negative predictor for preferences for Ford. As well as in males, some significant associations are difficult to explain.

The symbolic motives significantly negatively predicted preferences for Renault. The affective motives did not predict any car brand preferences. However, materialist values had greater impact on car brand preferences. These values were significant positive predictors for German "premium" brands, such as Audi, BMW, and Mercedes-Benz, as well as for French Renault.

The data indicated that for females, the attitudes to motoring were not the significant predictor for car brand preferences.

To understand the motivations for regular car driving and car and driving liking, we calculated multiple regressions. Motives (symbolic, affective, instrumental-reasoned, and independence) and materialistic values were chosen as the predictor variables (Table 5). The results indicated that the symbolic motives and the motives for independence were significant predictors for regular car driving, and the motives for independence had a greater effect (for males: $\mathrm{R}^{2}=0.33, \mathrm{~F}_{5,167}=16.239, p<0.001$, for females: $\mathrm{R}^{2}=0.28, \mathrm{~F}_{5,204}=16.012$, $p<0.001)$. In contrast, for car and driving liking in males, the affective motives, symbolic motives, and motives for independence were significant predictors of regular car driving, the symbolic motives had the greatest effect $\left(\mathrm{R}^{2}=0.39, \mathrm{~F}_{5,167}=21.135, p<0.001\right)$. For females, only the affective motives were significant predictors of car and driving liking $\left(\mathrm{R}^{2}=0.36\right.$, $\left.\mathrm{F}_{5,204}=24.681, p<0.001\right)$.

Table 5. Multiple regression of regular driving and cars and driving liking as predicted by motives (symbolic, affective, instrumental-reasoned, and independence) and materialist values calculated separately for males and females

\begin{tabular}{|c|c|c|c|c|c|c|c|c|c|c|}
\hline \multirow[b]{3}{*}{ Predictor } & \multicolumn{5}{|c|}{ Males } & \multicolumn{5}{|c|}{ Females } \\
\hline & $\beta$ & SE & B & $\mathrm{t}$ & $p$-value & $\beta$ & SE & B & $\mathrm{t}$ & $p$-value \\
\hline & \multicolumn{5}{|c|}{ Dependent variable: regular driving } & & & & & \\
\hline Symbolic & 0.14 & 0.08 & 0.18 & 1.89 & 0.06 & -0.06 & 0.07 & -0.10 & -0.93 & 0.35 \\
\hline Affective & 0.20 & 0.07 & 0.27 & 2.71 & 0.01 & 0.37 & 0.07 & 0.52 & 5.55 & 0.00 \\
\hline Instrumental & 0.05 & 0.07 & 0.08 & 0.69 & 0.19 & -0.02 & 0.07 & -0.02 & -0.25 & 0.80 \\
\hline Independence & 0.39 & 0.07 & 0.73 & 5.31 & 0.00 & 0.29 & 0.07 & 0.59 & 4.16 & 0.00 \\
\hline Materialism & 0.03 & 0.07 & -0.05 & -0.36 & 0.72 & 0.03 & 0.07 & 0.05 & 0.40 & 0.69 \\
\hline Predictor & \multicolumn{5}{|c|}{ Dependent variable: cars and driving liking } & & & & & \\
\hline Symbolic & 0.15 & 0.07 & 0.15 & 2.09 & 0.04 & 0.20 & 0.06 & 0.07 & 0.31 & 0.76 \\
\hline Affective & 0.43 & 0.07 & 0.47 & 6.29 & 0.00 & 0.58 & 0.06 & 0.56 & 9.45 & 0.00 \\
\hline Instrumental & -0.06 & 0.06 & -0.09 & -0.96 & 0.34 & -0.08 & 0.06 & -0.11 & -1.22 & 0.22 \\
\hline Independence & 0.27 & 0.07 & 0.40 & 3.80 & .000 & 0.10 & 0.07 & 0.12 & 1.53 & 0.13 \\
\hline Materialism & -0.13 & 0.07 & -0.22 & -1.93 & 0.05 & 0.02 & 0.06 & 0.03 & 0.38 & 0.70 \\
\hline
\end{tabular}

Note: The bold font indicates significance at $p<0.01$. 


\section{Conclusions}

In the present study, we examined the socio-psychological factors that influence car type preference in undergraduate students. First, we analysed the link between the personality traits of the Big-Five model of personality and the preference for particular car types. Although there is some evidence that there might be some relationships between personality and car preference, our study only identified weak and inconsistent relationships between personality traits and preferences for particular car types and brands. As could be predicted, we demonstrated that extraversion is positively associated with the preference for distinctive sports cars with a high performance. However, this tendency occurred only in males. Openness is positively associated with interest regarding alternative fuelling. Our findings suggest that the personality traits described by the Big-Five personality model are poor predictors of car preference.

However, personal motives for using cars have more noticeable impacts on the preferences for car types and brands. For men, symbolic and affective motives for car use had stronger effects on car preference compared with women. These motives predicted preferences for distinctive, powerful vehicles with higher equipment. In contrast, the instrumental-reasoned motives are not strongly linked to preferences for particular types of cars. It appears that in males, these motives lead to preferences for SUVs, large cars and interest in consumption, whereas in females these motives lead to preferences for alternative fuelling only. Materialist values are linked to preferences for well equipped cars.

In females, regular driving is associated with preferences for estates and off roads with diesel fuelling. Furthermore, in females, interests in cars and motoring are more associated with preferences for sports cars.

Furthermore, there is a question as to whether the preference for individual car brands is associated with certain personal features. The data indicated that individuals, both males and females, who prefer German premium brands, such as Audi, BMW, and Mercedes-Benz, have many features in common. For these individuals, the affective motives for owning a car are important. In males, this group also includes individuals who prefer Japanese brands, such as Nissan and Mitsubishi. Furthermore, the preferences for these brands are associated with a higher score of materialism. It appears that symbolic and affective motives are important predictors for car and driving liking, whereas regular car driving is influenced by both affective motives and motives of independence.

The results identified a clearly defined social subgroup of individuals who typically prefer German cars of "prestigious" branches. They have of materialistic values and namely affective motives are important motives for their car use and preference. Clearly, these individuals are inclined to frequently use the cars they own and are not interested in public transport. It can be assumed that they will not respond to appeals regarding social responsibility and environmental concerns. It appears that campaigns focused on these individuals should emphasize enjoyment from a journey in public transport, as well as the social prestige of this way of transport. For example, these requirements might be filled with the possibility to travel with modern trains equipped with Internet and other entertainment facilities. This strategy is present in the current campaign of some train operators. In accord with these 
claims, both state and private carriers in the Czech Republic started the campaign to gain new clients. The state carrier Czech Railways is promoting "new experiences of travelling" with the most modern trains Railjet. The private carrier Leo Express emphasizes that young educated individuals who care about the quality of services and love good clothing style and food prefer to travel with them.

It is worth noting that all described relationships had small size effects. It indicates the selected socio-psychological factors explained only a small portion of variance, and the actual car preferences of the participants from our sample were also influenced by other factors. Although there is evidence that car ownership, to some extent, can express the identities and social positions of their owners, some studies suggest that in the current young generation, the attitudes towards cars are changing. It might be that for undergraduate students, cars are not more important symbols of an individual's achievements, success, or identity. While previous generations seek freedom and flexibility through cars, recently, young individuals find their freedom and flexibility by staying connected to their friends and workplaces through their laptops or mobile phones (e.g., Belgiawan et al. 2014; Van, Fujii 2011). Thus, this may be one explanation for the small size effect identified in our data. It appears that the ownership of a car had more important functions in Czech society in previous decades in a transient period from the communist to free market system. At that time economically successful individuals had purchased Western cars, whereas "unsuccessful" individuals had only small or medium size cars manufactured in the Eastern bloc or no car at all. Current undergraduates could have different attitudes towards cars than the older generation. This potential value shift, which also appears in our data, should be further explored because this knowledge could be important for understanding attitudes towards cars in younger generations.

There might also be an additional explanation provided by the findings of Suitor et al. (2003). The authors reported that boys who attended private schools were less likely to gain prestige through car ownership than boys who attended public schools. However, the boys who attended private schools were more likely to gain prestige through general sociability and a good reputation. It is also possible that the undergraduates in our sample belong to individuals who gain their prestige through general sociability, travel experiences to attractive destinations or professional success.

The present study has several limitations. The survey was conducted at the University of Hradec Králové. The students predominately originate from the Hradec Králové and Pardubice regions. However, this deficiency is somewhat reduced by the fact that the Czech Republic currently has a relatively homogeneous socioeconomic composition (e.g., Viturka 2014). Nevertheless, we believe that our results provide evidence regarding the structure of vehicle preferences for young individuals in their twenties who attend university.

\section{Acknowledgements}

This research was funded by the project "Cognitive-behavioral analyses of human behaviors", 2015, Grant Agency of Excellence, University of Hradec Králové, Faculty of Informatics and Management. 


\section{References}

Adjemian, M. K.; Lin C.-Y. C.; Williams, J. 2010. Estimating spatial interdependence in automobile type choice with survey data, Transportation Research Part A: Policy and Practice 44(9): 661-675. http://dx.doi.org/10.1016/j.tra.2010.06.001

Anable, J.; Gatersleben, B. 2005. All work and no play? The positive utility of travel for work compared to leisure journeys, Transportation Research Part A: Policy and Practice 39: 163-181. http://dx.doi.org/10.1016/j.tra.2004.09.008

Belgiawan, P. F.; Schmöcker, J. D.; Fujii, S. 2014. Understanding car ownership motivations among Indonesian students, International Journal of Sustainable Transportation (in press). http://dx.doi.org/10.1080/15568318.2014.921846

Bhat, Ch. R.; Sen, S.; Eluru, N. 2009. The impact of demographics, built environment attributes, vehicle characteristics, and gasoline prices on household vehicle holdings and use, Transportation Research Part B: Methodological 43(1): 1-18. http://dx.doi.org/10.1016/j.trb.2008.06.009

Candler, J. 1991. Woman car buyer-don't call her a niche any more, Advertising Age 62(3): 58-59.

Carney, D. R.; Jost, J. T.; Gosling, S. D.; Potter, J. 2008. The secret lives of liberals and conservatives: personality profiles, interaction styles, and the things they leave blind, Political Psychology 29(6): 807-840. http://dx.doi.org/10.1111/j.1467-9221.2008.00668.x

Choo, S.; Mokhtarian, P. L. 2004. What type of vehicle do people drive? The role of attitude and lifestyle in influencing vehicle type choice, Transportation Research Part A: Policy and Practice 38(3): 201-222. http://dx.doi.org/10.1016/j.tra.2003.10.005

Dittmar, H. 1992. The social psychology of material possessions: to have is to be. Hemel Hempstead, UK: Wheatsheaf.

Dittmar, H. 2004. Are you what you have?, The Psychologist 17(4): 206-210.

Dunn, M.; Searle, R. 2010. Effect of manipulated prestige-car ownership on both sex attractiveness ratings, British Journal of Psychology 101: 69-80. http://dx.doi.org/10.1348/000712609X417319

Effendi, R. A. A. R. A.; Whitfield, T. W. A. 2012. He looks six years younger in that Porsche: do the qualities of products transfer to their owners?, Asian Social Science 8(15): 250-260. http://dx.doi.org/10.5539/ass.v8n15p250

Ellaway, A.; Macintyre, S.; Hiscock, R.; Kearns, A. 2003. In the driving seat: psychosocial benefits from private motor vehicle transport compared to public transport, Transportation Research Part F: Traffic Psychology and Behaviour 6(3): 217-231. http://dx.doi.org/10.1016/S1369-8478(03)00027-5

Fischer, J. 2009. A typology of car drivers [online]. Spiegel Institut Mannheim [cited 3 March 2015]. Available from Internet: http://www.spiegel-institut.de/en/presse/typology-car-drivers

Fraine, G.; Smith, S. G.; Zinkiewicz, L.; Chapman, R.; Sheenan, M. 2007. At home on the road? Can drivers' relationships with their cars be associated with territoriality?, Journal of Environmental Psychology 27: 204-214. http://dx.doi.org/10.1016/j.jenvp.2007.06.002

Gatersleben, B. 2007. Affective and symbolic aspects of car use: a review, in T. Gärling, L. Steg (Eds.). Threats to the quality of urban life from car traffic: problems, causes, and solutions. Amsterdam: Elsevier, 219-234.

Gatersleben, B. 2011. The car as a material possession. Exploring the link between materialism and car ownership and use, in K. Lucas, E. Blumenberg, R. Weinberger (Eds.). Auto motives. Understanding car use behaviours. Bingley, UK: Emerald Publishing Group, 137-148.

Gatersleben, B. 2014. Psychological motives for car use, in T. Gärling, D. Ettema, M. Friman. (Eds.). Handbook of sustainable travel. Dordrecht, The Netherlands: Springer Science, 85-94. http://dx.doi.org/10.1007/978-94-007-7034-8_6

Gärling, T.; Ettema, D.; Friman, M. 2013. Handbook of sustainablet travel. Dordrecht, The Netherlands: Springer Science. 
Gosling, S. D.; Ko, S. J.; Mannarelli, T.; Morris, M. E. 2002. A room with a cue: judgments of personality based on offices and bedrooms, Journal of Personality and Social Psychology 82: 379-398. http://dx.doi.org/10.1037/0022-3514.82.3.379

Gosling, S. D.; Rentfrow, P. J.; Swann, W. B. Jr. 2003. A very brief measure of the Big-Five personality domains, Journal of Research in Personality 37: 504-528. http://dx.doi.org/10.1016/S0092-6566(03)00046-1

John, O. P.; Srivastava, S. 1999. The Big Five trait taxonomy: history, measurement, and theoretical perspectives, in L. A. Pervin, O. P. John (Eds.). Handbook of personality: theory and research. New York: Guilford Press, 102-138.

Kitamura, R.; Akiyama, T.; Yamamoto, T.; Golob, T. F. 2001. Accessibility in a metropolis: toward a better understanding of land use and travel, Transportation Research Record: Journal of the Transportation Research Board 1780(1): 64-75.

Kühn, S.; Brick T. R.; Müller, B. C. N.; Gallinat, J. 2014. Is this car looking at you? How anthropomorphism predicts fusiform face area activation when seeing cars, PLoS ONE 9(12): e113885.

http://dx.doi.org/10.1371/journal.pone.0113885

Lave, Ch. A.; Train, K. 1979. A disaggregate model of auto-type choice, Transportation Research Part A: General 13(1): 1-9. http://dx.doi.org/10.1016/0191-2607(79)90081-5

Mannering, F.; Winston, C. 1985. A dynamic empirical analysis of household vehicle ownership and utilization, The Rand Journal of Economic 16(2): 215-236. http://dx.doi.org/10.2307/2555411

Manski, Ch. F.; Sherman, L. 1980. An empirical analysis of household choice among motor vehicles, Transportation Research Part A: General 14(5-6):349-366. http://dx.doi.org/10.1016/0191-2607(80)90054-0

Moutinho, L.; Davies, F.; Curry, B. 1996. The impact of gender on car buyer satisfaction and loyalty: a neural network analysis, Journal of Retailing and Consumer Services 3(3): 135-144. http://dx.doi.org/10.1016/0969-6989(95)00064-X

Naumann, L. P.; Vazire, S.; Rentfrow, P. J.; Gosling, S. D. 2009. Personality judgments based on physical appearance, Personality and Social Psychology Bulletin 35: 1661-1671.

http://dx.doi.org/10.1177/0146167209346309

Potoglou, D. 2008. Vehicle-type choice and neighbourhood characteristics: an empirical study of Hamilton, Canada, Transportation Research Part D: Transport and Environment 13(3): 177-186. http://dx.doi.org/10.1016/j.trd.2008.02.002

Rentfrow, P. J.; Gosling, S. D. 2003. The do re mi's of everyday life: the structure and personality correlates of music preferences, Journal of Personality and Social Psychology 84: 1236-1256. http://dx.doi.org/10.1037/0022-3514.84.6.1236

Richins, M. L. 2004. The material values scale: measurement properties and development of a short form, Journal of Consumer Research 31(1): 209-218. http://dx.doi.org/10.1086/383436

Steg, L. 2005. Car use: lust and must. Instrumental, symbolic and affective motives for car use, Transportation Research Part A: Policy and Practice 39(2-3): 147-162. http://dx.doi.org/10.1016/j.tra.2004.07.001

Steg, L.; Vlek, C.; Slotegraaf, G. 2001. Instrumental-reasoned and symbolic-affective motives for using a motor car, Transportation Research Part F: Traffic Psychology and Behaviour 4(3): 151-169. http://dx.doi.org/10.1016/S1369-8478(01)00020-1

Stieger, S.; Voracek, M. 2014. Not only dogs resemble their owners, cars do, too, Swiss Journal of Psychology 73(2): 111-117. http://dx.doi.org/10.1024/1421-0185/a000130

Suitor, J. J.; Powers, R. S.; Brown, R. 2003. Avenues to prestige among adolescents in public and religiously affiliated high schools, Adolescence 39(154): 229-241.

Van, H. T.; Fujii, S. 2011. A cross Asian country analysis in attitudes toward car and public transport, Journal of the Eastern Asia Society for Transportation Studies 9: 411-421.

Vazire, S.; Gosling, S. D. 2004. E-perceptions: personality impressions based on personal websites, Journal of Personality and Social Psychology 87: 123-132. http://dx.doi.org/10.1037/0022-3514.87.1.123 
Viturka, M. 2014. Integrative model for evaluation of development potentials of regions and its application on an example of the Czech Republic, $E \&$ M Economics and Management 17(4): 4-19. http://dx.doi.org/10.15240/tul/001/2014-4-001

Windhager, S.; Bookstein, F. L.; Grammer, K.; Oberzaucher, E.; Said, H.; Slice, D. E.; Thorstensen, T.; Schaefer, K. 2012. Cars have their own faces: cross-cultural ratings of car shapes in biological (stereotypical) terms, Evolution and Human Behavior 33(2): 109-120.

http://dx.doi.org/10.1016/j.evolhumbehav.2011.06.003

Denis ŠEFARA graduated from the Faculty of Informatics and Management at the University of Hradec Králové, where he is currently a PhD student in the Department of Management. His research includes the socio-psychological aspects of car choice and preference and eye tracking methods in environmental psychology.

Marek FRANĚK, PhD, is a Full Professor in Psychology in the Department of Management, Faculty of Informatics and Management at the University of Hradec Králové. He received his $\mathrm{PhD}$ in psychology from the University of Nijmegen in the Netherlands. His research includes environmental psychology, psychology of organization and music psychology.

Václav ZUBR graduated from the Faculty of Informatics and Management at the University of Hradec Kralove, where he is currently a PhD student in the Department of Management. His research includes knowledge management and learning organizations. 